\title{
Mental Illness and Mental Health: The Two Continua Model Across the Lifespan
}

\author{
Gerben J. Westerhof · Corey L. M. Keyes
}

Published online: 26 August 2009

(c) The Author(s) 2009. This article is published with open access at Springerlink.com

\begin{abstract}
Mental health has long been defined as the absence of psychopathologies, such as depression and anxiety. The absence of mental illness, however, is a minimal outcome from a psychological perspective on lifespan development. This article therefore focuses on mental illness as well as on three core components of positive mental health: feelings of happiness and satisfaction with life (emotional well-being), positive individual functioning in terms of self-realization (psychological well-being), and positive societal functioning in terms of being of social value (social well-being). The two continua model holds that mental illness and mental health are related but distinct dimensions. This model was studied on the basis of a cross-sectional representative internet survey of Dutch adults ( $N=1,340 ; 18-87$ years). Mental illness was measured with the Brief Symptom Inventory and mental health with the Mental Health Continuum Short Form. It was found that older adults, except for the oldestold, scored lower on psychopathological symptoms and were less likely to be mentally ill than younger adults. Although there were fewer age differences for mental health, older adults experienced more emotional, similar social and slightly lower psychological well-being. In sum, today's older adults have fewer mental illness problems, but they are not in a better positive mental health than
\end{abstract}

\footnotetext{
G. J. Westerhof $(\square)$

Psychology and Communication of Health and Risk, University of Twente, P.O. Box 217, 7500AE Enschede, The Netherlands

e-mail: g.j.westerhof@utwente.nl

C. L. M. Keyes

Department of Sociology, Emory University,

Atlanta, GA 30322, USA

e-mail: ckeyes@emory.edu
}

today's younger adults. These findings support the validity of the two continua model in adult development.

Keywords Mental illness - Mental health · Well-being · Lifespan development

\section{Introduction}

Mental health has been defined as the absence of mental illnesses such as depression or anxiety. Although it has important consequences for individual functioning and for society, mental illness represents only part of the outcomes from a psychological perspective on lifespan development. It is also important to study developmental outcomes in mental health beyond pathological outcomes by including the study of optimal mental health. For this purpose, we will define and study mental health as a positive phenomenon that is more than the absence of mental illness.

In this article, we will first present the two continua model of mental health and illness. After providing a definition of positive mental health, we present evidence that mental health and mental illness are related, yet distinct phenomena. In the next step, we will review studies on mental illness and mental health across the lifespan. There have been no studies to date which examined mental illness and mental health from a psychological perspective on lifespan development. In this article, we will test the two continua model in a nationally representative cross-sectional internet survey of Dutch adults between 18 and 87 years of age. The two continua model holds that it is possible that mental illness and mental health follow different age trajectories across adulthood, i.e., age groups that experience less mental illness do not necessarily experience better mental health. 
Positive Mental Health

The World Health Organization (WHO 2005, p. 2) has recently defined mental health as "a state of well-being in which the individual realizes his or her own abilities, can cope with the normal stresses of life, can work productively and fruitfully, and is able to make a contribution to his or her community". The three core components of this definition are (1) well-being, (2) effective functioning of an individual, and (3) effective functioning for a community (WHO 2005, p. 2). In further defining and operationalizing these core elements, we will draw on psychological and sociological research on the nature of well-being.

Two traditions of well-being research are currently distinguished: one focuses on hedonic well-being, the other on eudaimonic well-being (Keyes et al. 2002; Ryan and Deci 2001; Waterman 1993). Hedonic well-being involves feelings of happiness, satisfaction, and interest in life and will further be called emotional well-being (Keyes 2007). Waterman (1993) has argued that this is an empirical translation of the old Greek philosophy of hedonism, incorporated among others by Aristippus. In the social sciences, this tradition dates back to survey research in the 1960s and 1970s, when scholars started to study the quality of American life from the perspective of citizens themselves (Andrews and Withey 1976; Bradburn 1969; Campbell et al. 1976; Cantril 1965; Gurin et al. 1960). The goal of these studies was to monitor the well-being of the population and to improve social policies. At present, there is a widespread consensus that this type of well-being is a multidimensional concept, including evaluations of life in general in emotional terms (i.e., life satisfaction), and the presence of positive affects and the absence of negative affects (Diener 1984; Diener et al. 1999; Westerhof 2001).

In the 1980's and 1990's there was some discomfort with the narrow portrayal of well-being in the hedonic tradition (Ryff 1989; Waterman 1993). Psychologists started to reflect on the notion of well-being in terms of individual strivings and optimal functioning (Ryan and Deci 2001; Ryff 1989), which gave rise to the second tradition of research, called eudaimonic well-being. The concept of eudaimonia dates back to Aristotle, for whom not happiness, but the realization of one's own potentials was the essential element of a good life (Waterman 1993). The conceptual and empirical work of Ryff has become the most influential (Ryff 1989; Ryff and Essex 1991; Ryff and Keyes 1995). Ryff examined earlier psychological theories on optimal lifespan development (Erikson, Jung, Neugarten), on optimal functioning and self-actualization (Allport, Maslow, Rogers), and on positive mental health (Jahoda) and found six basic elements of positive functioning which repeatedly came back in this literature. Together these six elements make up what she calls psychological well-being
(Ryff 1989; Ryff and Keyes 1995). Each of them is important in the striving to become a better person and to realize one's potential:

1. Self-acceptance: a positive and acceptant attitude toward aspects of self in past and present;

2. Purpose in life: goals and beliefs that affirm a sense of direction and meaning in life;

3. Autonomy: self-direction as guided by one's own socially accepted internal standards;

4. Positive relations with others: having satisfying personal relationships in which empathy and intimacy are expressed;

5. Environmental mastery: the capability to manage the complex environment according to one's own needs;

6. Personal growth: the insight into one's own potential for self-development.

The work of Ryff, like other psychological work on eudaimonic well-being (Ryan and Deci 2001), focuses mainly on optimal functioning in terms of individual fulfillment. Keyes (1998) has argued that it is important to also study the optimal social functioning of individuals in terms of their social engagement and societal embeddedness. He therefore examined the work of classical sociologists and social psychologists, including Marx, Durkheim, Seeman, and Merton, to find indicators of what it means to prosper socially. His conceptual analysis indicates that social well-being consists of five dimensions describing a person who is functioning optimally in society:

1. Social coherence: being able to make meaning of what is happening in society;

2. Social acceptance: a positive attitude toward others while acknowledging their difficulties;

3. Social actualization: the belief that the community has potential and can evolve positively;

4. Social contribution: the feeling that one's activities contribute to and are valued by society;

5. Social integration: a sense of belonging to a community.

In our view, hedonic well-being and the psychological and societal aspects of eudaimonic well-being together make up the definition of positive mental health (Keyes 2005, 2007). They can be seen as subjective evaluations with respect to the core components of the World Health Organization's definition of positive mental health (Westerhof and Keyes 2008). Emotional well-being matches the core component of well-being in this definition. Psychological well-being is the subjective evaluation of optimal individual functioning and social well-being provides the subjective evaluation of optimal functioning for a community.

Keyes (2002) has argued that it takes a combination of emotional, psychological, and social well-being to be considered mentally healthy. He distinguishes flourishing 
as a state where individuals combine a high level of subjective well-being with an optimal level of psychological and social functioning. Similarly, languishing refers to a state where low levels of subjective well-being are combined with low levels of psychological and social wellbeing. Those who are not languishing or flourishing are considered to be in moderate mental health. This definition parallels the definition of depression in the DSM-IV, which includes both feelings of anhedonia (feeling sad or loss of interest and pleasure) and reported problems in functioning (such as problems in appetite, sleeping, or fatigue).

\section{The Two Continua Model of Mental Illness and Health}

Now that the concept of positive mental health has been clarified, an important question is how positive mental health relates to mental illness. The two continua model of mental illness and health holds that both are related, but distinct dimensions: one continuum indicates the presence or absence of mental health, the other the presence or absence of mental illness. Keyes (2005) studied the relation between mental health and mental illness using data from the study on Midlife Development in the United States (MIDUS), a representative survey of 3,032 American adults between the ages 25 and 74 . The data provide strong support for the two continua model: a confirmatory factor model with two related factors proved to be superior to the single-factor model and provided a nearly perfect fitting model to the MIDUS data (Keyes 2005). Mental health is therefore best viewed as a complete state, i.e., not merely the absence of mental illness but also the presence of mental health. Recently, this model has also been replicated in U.S. adolescents (ages 12-18; Keyes 2006), in Dutch adults (Westerhof and Keyes 2008) and in SouthAfrican adults (Keyes et al. 2008). Using other measures of mental illness and health, other studies have come to similar conclusions (Compton et al. 1996; Greenspoon and Saklofske 2001; Headey et al. 1993; Masse et al. 1998; Suldo and Shaffer 2008).

Keyes (2005) categorized individuals into those with and those without mental illness and into those with languishing, moderate, and flourishing mental health. Only $16.8 \%$ of the American adult population between 25 and 74 years had complete mental health as of 1995 (Keyes 2005). Two groups are of particular interest, as they do not fit the one-dimensional illness-health continuum. The first is a substantive group who is languishing but does not experience mental illness $(9.5 \%)$, the second group is mentally ill, but has nevertheless a moderate level of mental health (14.5\%).

Further evidence for the validity of the two continua model is given by studies on the relations of mental health and mental illness with other criteria. Findings consistently show that adults and adolescents who are diagnosed as anything less than in complete mental health (i.e., flourishing without mental illness) are functioning worse in terms of physical disease, healthcare utilization, work productivity, and psychosocial functioning (Keyes 2002, 2004, 2005, 2006, 2007). Interestingly, languishing individuals function as poorly on most outcomes as those with a mental illness. Most importantly, level of mental health distinguishes level of functioning among adults with a mental illness, and not only among those who are free of a mental illness. Thus, individuals who are flourishing but have an episode of mental illness function better (e.g., fewer missed days of work) than those with moderate mental health, who in turn function better than individuals who are languishing and have an episode of mental illness.

\section{Mental Illness and Mental Health Across the Lifespan}

Although many studies have examined lifespan trajectories of single dimensions of mental illness and well-being, there have been no studies to date on both mental illness and mental health across the adult lifespan. We therefore review the age differences in existing studies on different aspects of mental illness and mental health before explicating our hypotheses.

When mental health is viewed as the absence of symptoms of psychopathology such as depression, findings from studies on adulthood suggest that mental health is better in later phases of the adult lifespan. In the NEMESIS study, a representative study of Dutch adults between 18 and 65 years of age, it is found that the one-year prevalence of mental illness is lower in older than in younger groups, although the age differences depend on the type of illness studied (Bijl et al. 1998). The aforementioned MIDUS study showed that major depression is found less often in older than in younger adults, varying in age between 25 and 74 years (Kessler et al. 2004). In their review of studies on depression in adults aged 55 and over, Beekman et al. (1999) conclude that most studies concur that the prevalence of major depression is lower in this group than in younger age groups. Studies on depressive symptoms - as opposed to diagnosis-produce more contradictory results when comparing older to younger adults, but studies focusing on those over 55 years of age found more depressive symptoms in the old-old than in the young-old. In a summary of five large-scale population studies of over 18,000 respondents between the ages of 18 and 99 years, Mirowsky and Ross (1999) reported that the number of days of depression declines between the ages of 18 and about 62 , but increases between the ages of about 63 and 99. Although there are variations according to the kinds of pathology studied and the exact definitions and measures used, these studies suggest that there is a 
curvilinear relationship between age and mental illness: mental illness is less prevalent among older than younger adults, but is again found more often during the last phase of life.

With regard to mental health, most studies have addressed emotional well-being. Research has found remarkably few age differences in life satisfaction in adulthood, but positive affect is consistently found to be somewhat lower in older than younger adults (Diener and Suh 1998: adults in their 20s through their 80s; Mroczek and Kolarz 1998: 25-74 years; Westerhof 2001: 40-85 years). When differences in agerelated life circumstances are also taken into account, older adults (70-85 years) report even higher levels of life satisfaction than middle-aged adults (40-54 years; Westerhof 2001). Studies on psychological well-being have found that self-acceptance and positive relations with others are unrelated to age (Ryff and Essex 1991 compared three groups with mean ages of 20, 50, and 75 years; Ryff and Keyes 1995 studied adults 25 years and older). Older adults experience more autonomy and environmental mastery than younger adults, but less personal growth and purpose in life. A largescale representative German survey on the eudaimonic concept of meaning in life has also shown that there are few age differences in the second half of life (Read et al. 2005; 40-85 years). A meta-analysis of 70 studies including samples with a mean age of 40 years and older showed that older adults experience somewhat less meaning in life than younger adults, but age only accounts for $1.4 \%$ of the explained variance (Pinquart 2001). Studies on social wellbeing have shown that older adults experience more social acceptation and social integration than younger adults, but they report less social coherence and less social contribution (Keyes 1998; Keyes and Shapiro 2004). There are no age differences for social actualization. It can be concluded that age differences depend on the aspect of mental health under study. When summing the results across the different aspects, these studies suggest that the mental health of individuals of different ages does not differ much.

Taking the findings on mental illness and mental health together, existing studies suggest that older persons-except for the oldest-old-are better-off in terms of mental illness than younger adults, but not in terms of signs of positive mental health. Because mental illness and health follow different age trajectories, they are indeed qualitatively different dimensions. Hence, these studies would provide support for the two continua model. However, the results are not conclusive, as they come from different studies focusing on different aspects in different age groups.

Our study is the first to examine whether mental illness and mental health vary simultaneously across the lifespan. We expect that older persons will be better in terms of mental illness-except for the oldest-old. We also expect that age groups will be similar in terms of mental health.
In the present study, we take two approaches to assess these hypotheses. We will first study the age differences in mean levels of mental illness and the three core components of mental health: emotional, psychological, and social well-being. Second, using a person-centered approach, we will study age differences in the chances of being completely mentally ill (i.e., mental illness without flourishing) or completely mentally healthy (i.e., flourishing without mental illness). As age differences might be related to agegraded differences in life circumstances, we will also control for a number of characteristics of the life contexts of Dutch adults.

\section{Method}

\section{Subjects}

In this article, data of the LISS-panel of CentERdata are used. The LISS-panel (Longitudinal Internet Study in the Social Sciences) comprises Dutch-speaking non-institutionalized individuals from 5,000 households in the Netherlands. Members answer internet-based questionnaires on a monthly basis. The questions on mental health and illness were presented to one person per household in one-third of the households. This subsample was stratified according to age $(18-29$, 30-49, 50-64, 65+ years), gender, and migratory status. This procedure resulted in a sample of 1,662 respondents who filled out the questionnaire in December 2007 (a response of $76 \%$ of those who participated in the panel). Some basic characteristics of the sample are presented in Table 1. Half of the sample is female. Fourteen percent were born abroad or had at least one of their parents born abroad: about one-third comes from Western countries and two-thirds from Non-Western countries. One-third has more than 12 years education. Almost half of the respondents have a monthly income higher than 2,600 Euros. Somewhat more than half of them are married and half of them have paid work. The present subsample consists of individuals with a somewhat higher educational attainment than the Dutch population.

\section{Instruments}

The Mental Health Continuum-Short Form (MHC-SF; Keyes 2006; Keyes et al. 2008) consists of 14 items which correspond to our theoretical formulation of emotional, psychological, and social well-being. Sample items for the three types of well-being are "In the past month, how often did you feel: ...happy?; ...that your life has a sense of direction or meaning to it? ...that people are basically good?". This innovative instrument was derived from longer scales measuring the three types of well-being 
Table 1 Major characteristics of the respondents $(N=1,340)$

\begin{tabular}{|c|c|}
\hline & Percen \\
\hline \multicolumn{2}{|l|}{ Gender } \\
\hline Female & 50.0 \\
\hline Male & 50.0 \\
\hline \multicolumn{2}{|l|}{ Migrant } \\
\hline No & 86.0 \\
\hline Yes, Western country & 5.0 \\
\hline Yes, Non-Western country & 9.0 \\
\hline \multicolumn{2}{|l|}{ Education } \\
\hline Primary (6 yrs.) & 31.3 \\
\hline Lower vocational (10 yrs.) & 11.5 \\
\hline Secondary (11-12 yrs.) & 22.0 \\
\hline Middle vocational (13 yrs.) & 23.0 \\
\hline Higher vocational (15 yrs.) & 8.1 \\
\hline University (16 yrs.) & 4.0 \\
\hline \multicolumn{2}{|l|}{ Monthly household income } \\
\hline$\leq 1,150$ Euro & 8.9 \\
\hline 1,151-1,800 Euro & 21.6 \\
\hline $1,801-2,600$ Euro & 25.4 \\
\hline$>2,600$ Euro & 44.2 \\
\hline \multicolumn{2}{|l|}{ Marital status } \\
\hline Married & 54.3 \\
\hline Divorced & 9.3 \\
\hline Widowed & 6.3 \\
\hline Never married & 30.1 \\
\hline \multicolumn{2}{|l|}{ Employment status } \\
\hline Paid work & 50.7 \\
\hline Unemployed & 1.9 \\
\hline Disabled & 2.8 \\
\hline School or study & 7.2 \\
\hline Retired & 23.5 \\
\hline Household & 10.5 \\
\hline Other & 3.5 \\
\hline
\end{tabular}

(Cantril 1965; Mroczek and Kolarz 1998; Ryff and Keyes 1995; Keyes 1998, 2005). It was translated in Dutch and back into English and subsequently used in five Dutch pilot studies where it obtained good psychometric properties. Using exploratory factor analysis, we reproduced the three factors in the LISS-panel: emotional, psychological, and social well-being (Westerhof and Keyes 2008). The internal consistency (Cronbach alpha) for the three scales is .83 for emotional well-being, .83 for psychological well-being, and .74 for social well-being. The reliability of the total scale is .89. We computed mean scores for emotional, psychological, and social well-being. Furthermore, we divided the sample into two groups: those who are flourishing (34.9\%) and those who are not (65.1\%). Individuals who scored almost everyday or everyday on at least one of the three items measuring emotional well-being and on at least six of the 11 items measuring psychological and social well-being were diagnosed as flourishing (Keyes 2005).

The Brief Symptom Inventory (BSI) is the most widely used instrument in American mental health care to measure mental problems (Derogatis 1975). Sample items are "During the past 7 days, how much were you distressed by nervousness or shakiness inside?" and "During the past 7 days, how much were you distressed by feeling afraid to travel on buses, subways, or trains?". The Dutch translation has recently been validated (de Beurs and Zitman 2006). The BSI measures Somatization, Obsessive-compulsive Complaints, Interpersonal Sensitivity (social phobia), Depression, Anxiety, Hostility, Phobic Anxiety, Paranoid Ideation, and Psychoticism. The reliability of the total scale in the present sample is .95 (Cronbach alpha). We computed the mean score on the BSI. Those with a mean score of .70 or higher are identified as possible cases of mental illness according to the Dutch manual of the BSI (de Beurs 2006). We subsequently divided the sample into two groups: those with mental illness (12.9\%) and without mental illness $(87.1 \%)$.

For the person-centered analyses, we combined the dichotomous variables on flourishing and mental illness. Those who were flourishing without mental illness were seen as in complete mental health $(N=543 ; 32.7 \%)$. Those who were classified as being mentally ill, but not as flourishing were classified as in complete illness $(N=177$; $10.6 \%)$. All others were classified as in moderate mental health $(N=943 ; 56.7 \%)$.

Data of the respondents also included age, gender, migration status, educational level, marital, and employment status (see Table 1). The age of the respondents varied between 18 and 87 (Mean $=48.32$; SD = 17.66). Three measures of physical health were used: number of physical conditions, number of limitations in activities of daily living, and subjective health. The number of physical conditions was measured with a checklist, asking whether a physician had told the respondent during the last year that he or she suffered from any of 18 possible physical conditions (Mean $=0.79 ; \quad \mathrm{SD}=1.31$ ). Limitations in basic and instrumental activities of daily living were measured as the mean on 23 activities (from $1=$ without problems to $4=$ only with help from others; Mean $=1.16$; $\mathrm{SD}=0.26$ ). Subjective health was measured with a single question asking how respondents rate their present health $(1=$ bad to $5=$ excellent; Mean $=3.13 ; \mathrm{SD}=0.76$ ).

\section{Analyses}

There are complete data on all variables for 1,340 respondents. There were missing values on income because 
of refusals $(N=147)$, and on the health variables because not all respondents had been presented the module with health questions $(N=165)$. A logistic regression analysis on those who had missing data versus those who had complete data showed that none of the other variables (age, gender, migration status, educational level, marital and employment status, mental illness, and mental health) was significantly related to having missing data. We therefore analyzed only those who had complete data.

We used two approaches to assess the hypothesis that older adults, except for the oldest group, experienced less mental illness than younger adults, but a similar mental health. We first carried out four two-step hierarchical OLS regression analyses to assess the relations of age with the level of mental illness and mental health (as measured with the Brief Symptom Inventory and the three subscales of the Mental Health Continuum, i.e., emotional, psychological, and social well-being). In the first step, we used age and agesquared as independent variables to detect possible linear and curvilinear relationships. Age was centered on the mean to avoid collinearity with age-squared. In the second step, we added the control variables gender, migration status, educational level, marital status, employment, and health.

Secondly, we used a two-step multinomial regression analysis for the person-centered analysis of age differences. The dependent variable is constituted by three groups: those with complete mental health (flourishing, but no illness), those with complete mental illness (illness, but not flourishing), and those with a moderate mental health. The last group served as the reference group. In the first step we entered age and age-squared and in the second step we added the control variables (gender, migration status, educational level, marital status, employment, and health).

\section{Results}

We were first interested in the relation of age with the level of mental illness and mental health. The results of the hierarchical regression analyses are reported in Table 2. For mental illness, we found a significant effect of age as well as a significant effect of age-squared (Table 2, first column of results). These findings reveal that mental illness is found less often among today's older adults, but not among today's oldest-old. Figure 1 portrays this finding: mental illness problems are found less often in each successive age group until age 70 but not afterwards. The effect of age-squared disappeared when the control variables (gender, migration status, educational level, marital status, employment, and health) were added to the analyses (Table 2, second column of results), but the linear effect of age remained significant and even almost doubled. It can be concluded that older adults would even experience lower levels of mental illness, were it not for their worse life contexts.

When analyzing the separate components of mental health, there was a positive relation between age and emotional well-being, a negative relationship between age and psychological well-being, and there was no association between age and social well-being (Table 2, third, fifth, and seventh column of results). We found no effects of agesquared, indicating that the relationships of age to emotional and psychological well-being are not curvilinear. As can also be seen in Fig. 1, today's older adults experience more emotional well-being, but less psychological well-being than today's younger adults. The age effects remained significant when the control variables (gender, migration status, educational level, marital status, employment, and health) were entered in the equation, although the coefficient for

Table 2 Ordinary least squares regression of mental illness and mental health on age and living conditions $(N=1,340)$

\begin{tabular}{|c|c|c|c|c|c|c|c|c|}
\hline & \multicolumn{2}{|c|}{ Mental illness } & \multicolumn{2}{|c|}{ Emotional well-being } & \multicolumn{2}{|c|}{ Social well-being } & \multicolumn{2}{|c|}{ Psychological well-being } \\
\hline & Beta & Beta & Beta & Beta & Beta & Beta & Beta & Beta \\
\hline Age (centered) & $-.16 * * *$ & $-.29 * * *$ & $.06^{*}$ & $.07 *$ & -.01 & .03 & $-.15 * * *$ & $-.10 * *$ \\
\hline Age squared & $.06^{*}$ & -.02 & .04 & $.08 *$ & -.01 & -.01 & -.01 & .00 \\
\hline Gender: Female & & .00 & & $.05^{*}$ & & .00 & & $.06^{*}$ \\
\hline Migration: Yes & & .05 & & $-.05 *$ & & .02 & & .01 \\
\hline Education & & .00 & & .01 & & .06 & & $.08^{* *}$ \\
\hline Household income & & $-.09 * *$ & & .00 & & -.02 & & -.04 \\
\hline Married: Yes & & -.04 & & $.14 * * *$ & & -.03 & & -.01 \\
\hline Employed: Yes & & -.05 & & -.02 & & .01 & & .03 \\
\hline ADL-limitations & & $.22 * * *$ & & $-.08 *$ & & -.01 & & -.03 \\
\hline Number of illnesses & & $.11 * * *$ & & -.03 & & .01 & & .04 \\
\hline Subjective health & & $-.18 * * *$ & & $.23 * * *$ & & $.12 * * *$ & & $.16^{* * * *}$ \\
\hline Adjusted $R^{2}$ & .03 & .20 & .00 & .10 & .00 & .01 & .02 & .05 \\
\hline
\end{tabular}

$* p<.05 ; * * p<.01 ; * * * p<.001$ 
Fig. 1 Mean levels of mental illness and three components of mental health by age group $(N=1,340)$

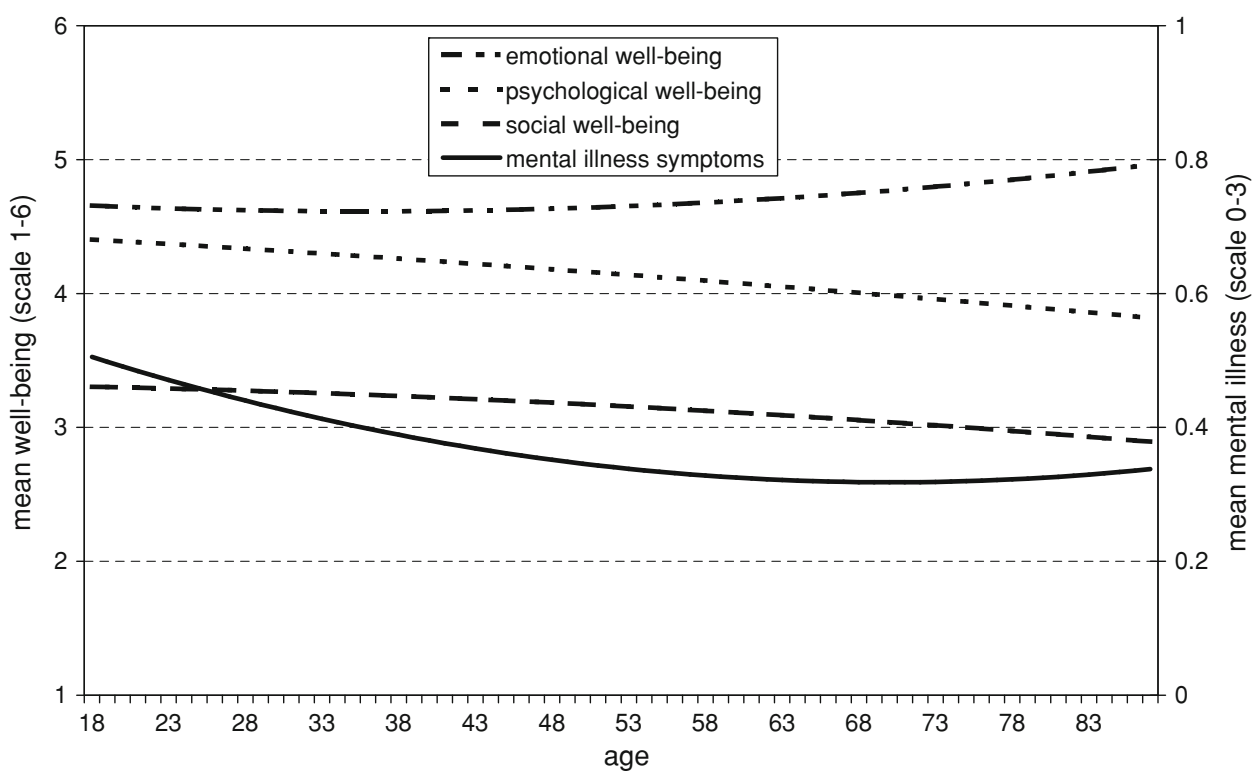

psychological well-being decreased by one-third. Furthermore, there was a significant effect of age-squared for emotional well-being. This finding shows that the higher levels of emotional well-being in older adults even accelerate in higher age groups, when controlled for life contexts.

Examining the effects of the indicators for life contexts shows that a better subjective health is consistently related to a higher level of mental illness and a lower level of mental health. However, the other independent variables show a differentiated pattern of associations with mental illness and the three components of mental health. These findings provide further evidence that it is important to distinguish mental illness and mental health as well as emotional, psychological, and social well-being.

In general, we can conclude that today's older persons experience fewer mental illness problems than today's younger persons. The findings for mental health are mixed: the current cohort of older persons have a better emotional well-being, a worse psychological well-being and a similar social well-being, when compared to the current cohort of younger adults.

\section{Person-Centered Analyses}

We used a multinomial regression analysis for the personcentered analysis of age differences. The dependent variable consists of three groups: those with complete mental health (flourishing, but no illness), those with complete mental illness (illness, but not flourishing) and those with a moderate mental health. The last group served as the reference group.

The first two columns of Table 3 show the results of the first analysis, including age and age-squared. We find significant age differences with regard to complete mental health and illness: older persons have lower odds of falling in the groups with complete mental illness or with complete mental health as compared to moderate mental health. There are no effects of age-squared, showing that the age differences are not curvilinear. When the control variables are entered, there are no age differences with regard to complete mental health anymore, but the age differences with regard to complete mental illness continue to exist, with today's older adults being less likely to have complete mental illness.

Interestingly, the control variables that are related to complete mental health (i.e., gender and migrant) are distinct from those that predict complete mental illness (i.e., being married, being employed and the number of physical conditions). Only subjective health is related to both complete mental health and mental illness. These findings give additional support to the two-continua model of mental health and illness. That is, the predictors of the presence of positive mental health are often distinct from the predictors of the absence of mental illness.

\section{Conclusion}

The present study was the first attempt to investigate both mental illness and mental health in a representative survey including adults between 18 and 87 years of age. The hypothesis that older adults experience less mental illness, except the oldest-old, was confirmed. The expected higher levels of mental illness problems in the oldest adults could be explained by age-related differences in life circumstances. Furthermore, the person-centered analysis showed that there are no curvilinear relations between age and complete mental illness. We therefore conclude that today's 
Table 3 Multinomial regression of categories of mental health and illness on age and indicators of life circumstances $(N=1,340)$

\begin{tabular}{|c|c|c|c|c|c|c|}
\hline & \multicolumn{3}{|l|}{ Step 1} & \multicolumn{3}{|l|}{ Step 2} \\
\hline & $\begin{array}{l}\text { Complete } \\
\text { illness } \\
\text { Beta }\end{array}$ & $\begin{array}{l}\text { Moderate } \\
\text { mental health } \\
\text { (ref.) }\end{array}$ & $\begin{array}{l}\text { Complete } \\
\text { health } \\
\text { Beta }\end{array}$ & $\begin{array}{l}\text { Complete } \\
\text { illness } \\
\text { Beta }\end{array}$ & $\begin{array}{l}\text { Moderate } \\
\text { mental health } \\
\text { (ref.) }\end{array}$ & $\begin{array}{l}\text { Complete } \\
\text { health } \\
\text { Beta }\end{array}$ \\
\hline Age (centered) & $.97 * * *$ & - & $.99 *$ & $.96 * * *$ & - & 1.00 \\
\hline Age squared & 1.00 & - & 1.00 & 1.00 & - & 1.00 \\
\hline Gender: Female & & & & 1.12 & - & $1.43 * *$ \\
\hline Migration: Yes & & & & 1.59 & - & $1.49 *$ \\
\hline Education & & & & 1.01 & - & 1.09 \\
\hline Household income & & & & .87 & - & 1.00 \\
\hline Married: Yes & & & & $.62 *$ & - & .79 \\
\hline Employed: Yes & & & & $.58 *$ & - & 1.01 \\
\hline ADL-limitations & & & & 1.73 & - & .83 \\
\hline Number of illnesses & & & & $1.15^{*}$ & - & 1.02 \\
\hline Subjective health & & & & $.45^{* * *}$ & - & $1.35^{* *}$ \\
\hline Pseudo- $R^{2}$ (Nagelkerke) & .03 & & & .15 & & \\
\hline
\end{tabular}

$* p<.05 ; * * p<.01 ; * * * p<.001$

older adults experience less mental illness than today's younger adults.

The hypothesis that there are no age differences in mental health receives partial support. When compared to the current cohort of younger adults, older adults experience more emotional, similar social and less psychological well-being. They are less often classified as being in complete mental health, but this finding can be explained by age-related differences in life circumstances. We therefore conclude that overall today's older adults indeed experience similar amounts of mental health as today's younger adults.

The findings of this study provide strong support for the two continua model of mental illness and health (Keyes 2002, 2005, 2007). Even though they experience less mental illness than younger adults, the current cohort of older adults is not in better positive mental health. Conversely, younger adults have more mental illness, yet they do not have less positive mental health than older adults. These findings would not have been possible when mental illness and mental health are the endpoints of one single continuum.

Additional support for the two continua model is provided by the differential relations of background characteristics to mental illness and mental health. Subjective health is the strongest correlate of both mental illness and mental health, but other characteristics show different relations with mental illness and mental health.

An important question remains how the age differences can be explained. We could show that age-related differences in life contexts play an important role. When life conditions are taken into account older adults experience even fewer mental illness problems. The curvilinear effect is also explained by the differences in life contexts. Furthermore, individuals in the oldest age groups even experience more emotional well-being as indicated by the curvilinear relation with age-squared and part of the differences in psychological well-being are explained. Age differences in complete mental health are also explained by life contexts. However, the linear relationship of age with mental illness as well as with emotional and psychological well-being remained after controlling for the background characteristics.

The present survey is limited in further clarifying the age differences due to its cross-sectional nature. There are different explanations for the lower levels of mental illness in older persons which could direct further research on this topic using longitudinal studies. First, there might have been a cohort effect, i.e., cultural historical changes may be related to the higher prevalence of mental health in younger cohorts. The Dutch NEMESIS study has found for example that the lifetime prevalence of different mental disorders is indeed lower in older than in younger adults (Bijl et al. 1998). This has also been reported in studies of other national populations (e.g., Lewinsohn et al. 1993). A meta-analysis has also shown that anxiety is more prevalent in more recent cohorts of young adults (Twenge 2000). A second explanation might be a survival effect: those who experience more mental illness are more likely to die at a younger age, so that only the resilient adults survive and grow older. Last, older adults might be better in dealing with negative emotions, also in relation to their increased life experience. Socio-emotional selectivity theory proposed a positivity effect in later life: "a developmental pattern that has emerged in which a selective focus on negative stimuli in youth shifts to a relatively stronger 
focus on positive information in old age" (Carstensen 2006, p. 1915). This positivity effect might explain the finding that older persons experience fewer mental illness problems and more emotional well-being. However, it does not explain the similarities and differences between age groups in social or psychological functioning.

Older adults do not flourish more than younger adults, despite the fact that they experience fewer mental illness problems. The finding that older adults experience less psychological well-being is in line with other findings showing that older adults experience less meaning in life (Pinquart 2001). One explanation for this finding would be the structural lag, i.e., society's failure to provide meaningful opportunities for self-realization for older adults (cf. Westerhof et al. 2003). Another explanation would be that older adults compensate the lack of psychological wellbeing by a higher emotional well-being. Interestingly, the different trajectories for emotional and psychological wellbeing were also found in the MIDUS study (Keyes et al. 2002). But again, the cross-sectional nature of the present study does not allow to disentangle these different explanations, which provide interesting hypotheses for future research.

Although more research is needed on the causes of mental illness and mental health across the lifespan, the present study makes clear that the absence of mental illness falls short as a criterion in studying mental health as a developmental outcome across the adult lifespan. Indicators of positive mental health need to be taken into account as well.

Open Access This article is distributed under the terms of the Creative Commons Attribution Noncommercial License which permits any noncommercial use, distribution, and reproduction in any medium, provided the original author(s) and source are credited.

\section{References}

Andrews, F. M., \& Withey, S. B. (1976). Social indicators of wellbeing: Americans' perceptions of life quality. New York: Plenum.

Beekman, A. T. F., Copeland, J. R. M., \& Prince, M. J. (1999). Review of community prevalence of depression in later life. British Journal of Psychiatry, 174, 307-311.

Bijl, R. V., Ravelli, A., \& Van Zessen, (1998). Prevalence of psychiatric disorder in the general population: Results of the Netherlands Mental Health Survey and Incidence Study (NEMESIS). Social Psychiatry and Psychiatric Epidemiology, 33, 587-595.

Bradburn, N. M. (1969). The structure of psychological well-being. Chicago: Aldine.

Campbell, A., Converse, P. E., \& Rodgers, W. L. (1976). The quality of American life: Perceptions, evaluations and satisfactions. New York: Russell Sage.

Cantril, H. (1965). The pattern of human concerns. New Brunswick, NJ: Rutgers University Press.
Carstensen, L. L. (2006). The influence of a sense of time on human development. Science, 312, 1913-1915.

Compton, W. C., Smith, M. L., Cornish, K. A., \& Qualls, D. L. (1996). Factor structure of mental health measures. Journal of Personality and Social Psychology, 71, 406-413.

de Beurs, E. (2006). Brief Symptom Inventory: Handleiding. Leiden: PITS.

de Beurs, E., \& Zitman, F. (2006). De Brief Symptom Inventory (BSI): De betrouwbaarheid en validiteit van een handzaam alternatief. Maandblad Geestelijke Volksgezondheid, 61, $120-141$.

Derogatis, L. R. (1975). The Brief Symptom Inventory. Baltimore, MD.: Clinical Psychometric Research.

Diener, E. (1984). Subjective well-being. Psychological Bulletin, 95, $542-575$.

Diener, E., \& Suh, E. M. (1998). Subjective well-being and age: An international analysis. Annual Review of Gerontology and Geriatrics, 17, 304-324.

Diener, E., Suh, E. M., Lucas, R., \& Smith, H. L. (1999). Subjective well-being: Three decades of progress. Psychological Bulletin, 125, 276-302.

Greenspoon, P. J., \& Saklofske, D. H. (2001). Toward an integration of subjective well-being and psychopathology. Social Indicators Research, 54, 81-108.

Gurin, G., Veroff, J., \& Feld, S. (1960). Americans view their mental health. New York: Basic Books.

Headey, B., Kelley, J., \& Wearing, A. (1993). Dimensions of mental health: Life satisfaction, positive affect, anxiety, and depression. Social Indicators Research, 29, 63-82.

Kessler, R. C., Mickelson, K. D., Walters, E. E., Zhao, S., \& Hamilton, L. (2004). Age and depression in the MIDUS Survey. In O. G. Brim, C. D. Ryff, \& R. C. Kessler (Eds.), How healthy are we: A national study of well-being at midlife (pp. 227-251). Chicago: University of Chicago Press.

Keyes, C. L. M. (1998). Social well-being. Social Psychology Quarterly, 61, 121-140.

Keyes, C. L. M. (2002). The mental health continuum: From languishing to flourishing in life. Journal of Health and Social Behavior, 43, 207-222.

Keyes, C. L. M. (2004). The nexus of cardiovascular disease and depression revisited: The complete mental health perspective and the moderating role of age and gender. Aging and Mental Health, 8, 266-274.

Keyes, C. L. M. (2005). Mental illness and/or mental health? Investigating axioms of the complete state model of health. Journal of Consulting and Clinical Psychology, 73, 539-548.

Keyes, C. L. M. (2006). Mental health in adolescence: Is America's youth flourishing? American Journal of Orthopsychiatry, 76, 395-402.

Keyes, C. L. M. (2007). Promoting and protecting mental health as flourishing: A complementary strategy for improving national mental health. American Psychologist, 62, 95-108.

Keyes, C. L. M., \& Shapiro, A. D. (2004). Social well-being in the United States: A descriptive epidemiology. In O. G. Brim, C. D. Ryff, \& R. C. Kessler (Eds.), How healthy are we: A national study of well-being at midlife (pp. 350-373). Chicago: University of Chicago Press.

Keyes, C. L. M., Shmotkin, D., \& Ryff, C. D. (2002). Optimizing well-being: The empirical encounter of two traditions. Journal of Personality and Social Psychology, 82, 1007-1022.

Keyes, C. L. M., Wissing, M., Potgieter, J., Temane, M., Kruger, A., \& van Rooy, S. (2008). Evaluation of the Mental Health Continuum-Short Form (MHC-SF) in Swetsana-speaking South Africans. Clinical Psychology and Psychotherapy, 15, 181-192. 
Lewinsohn, P. M., Rohde, P., Seeley, J. R., \& Fischer, S. A. (1993). Age-cohort changes in the lifetime occurrence of depression and other mental disorders. Journal of Abnormal Psychology, 102, $110-120$.

Masse, R., Poulin, C., Dassa, C., Lambert, J., Belair, S., \& Battaglini, A. (1998). The structure of mental health higher-order confirmatory factor analyses of psychological distress and wellbeing measures. Social Indicators Research, 45, 475-504.

Mirowsky, J., \& Ross, C. E. (1999). Well-being across the life course. In A. V. Horwitz \& T. L. Scheid (Eds.), A handbook for the study of mental health: Social contexts, theories, and systems (pp. 328-347). New York: Cambridge University Press.

Mroczek, D. K., \& Kolarz, C. M. (1998). The effect of age on positive and negative affect: A developmental perspective on happiness. Journal of Personality and Social Psychology, 75, 1333-1349.

Pinquart, M. (2001). Creating and maintaining purpose in life in old age: A meta-analysis. Ageing International, 27, 90-114.

Read, S., Westerhof, G. J., \& Dittmann-Kohli, F. (2005). Challenges to meaning in life: A comparison in four different age groups in Germany. International Journal of Aging and Human Development, 61, 85-104.

Ryan, R. M., \& Deci, E. L. (2001). On happiness and human potentials: A review of research on hedonic and eudaimonic well-being. Annual Review of Psychology, 52, 141-166.

Ryff, C. D. (1989). Happiness is everything, or is it? Explorations on the meaning of psychological well-being. Journal of Personality and Social Psychology, 57, 1069-1081.

Ryff, C. D., \& Essex, M. J. (1991). Psychological well-being in adulthood and old age: Descriptive markers and explanatory processes. Annual Review of Gerontology and Geriatrics, 10, 144-171.

Ryff, C. D., \& Keyes, C. L. M. (1995). The structure of psychological well-being revisited. Journal of Personality and Social Psychology, 69, 719-727.

Suldo, S. M., \& Shaffer, E. J. (2008). Looking beyond psychopathology: The dual-factor model of mental health in youth. School Psychology Review, 37, 52-68.

Twenge, J. M. (2000). The age of anxiety? Birth cohort change in anxiety and neuroticism, 1952-1993. Journal of Personality and Social Psychology, 79, 1007-1021.

Waterman, A. S. (1993). Two conceptions of happiness: Contrasts of personal expressiveness (eudaimonia) and hedonic enjoyment. Journal of Personality and Social Psychology, 64, 678-691.

Westerhof, G. J. (2001). Wohlbefinden in der zweiten Lebenshälfte [Well-being in the second half of life]. In F. Dittmann-Kohli, C. Bode, \& G. J. Westerhof (Eds.), Die zweite LebenshälftePsychologische Perspektiven. Ergebnisse des Alters-Survey (pp. 79-128). Stuttgart: Kohlhammer.

Westerhof, G. J., Dittmann-Kohli, F., \& Bode, C. (2003). The aging paradox: Towards personal meaning in gerontological theory. In S. Biggs, A. Lowenstein, \& J. Hendricks (Eds.), The need for theory: Social gerontology for the 21st century (pp. 127-143). Amityville, NY: Baywood.

Westerhof, G. J., \& Keyes, C. L. M. (2008). Geestelijke gezondheid is meer dan de afwezigheid van geestelijke ziekte [Mental health is more than the absence of mental illness]. Maandblad Geestelijke Volksgezondheid, 63, 808-820.

World Health Organization. (2005). Promoting mental health: Concepts, emerging evidence, practice. Geneva: WHO. 